\title{
A preliminary study: saltiness and sodium content of aqueous extracts from plants and marine animal shells
}

\author{
Yawei Zhang $\cdot$ Qiaofen Cheng $\cdot$ Yao Yao $\cdot$ Xiuyun Guo \\ Rongrong Wang $\cdot$ Zengqi Peng
}

Received: 8 May 2013 / Revised: 20 November 2013 / Accepted: 27 November 2013 / Published online: 12 December 2013

(C) The Author(s) 2013. This article is published with open access at Springerlink.com

\begin{abstract}
To develop a salt substitute with low sodium content, the water-soluble components of seaweed, kelp, clamshell, oyster shell, semen cassiae, cuttlefish bone, inula flower, Arabia cowry shell, and sanna leaf were extracted with water. The aqueous extracts of nine species of plants and marine animal shells were obtained after drying the plants and shells at $105{ }^{\circ} \mathrm{C}$ until achieving a constant weight. The hedonic scale test revealed that the clamshell and cuttlefish bone aqueous extracts tasted distinctly salty. The result of the degree of difference test showed that the $1 \%$ clamshell extract solution $(\mathrm{m} / \mathrm{v})$ and $0.6 \%$ cuttlefish bone extract solution $(\mathrm{m} / \mathrm{v})$ both had equivalent saltiness of $0.6 \% \mathrm{NaCl}(\mathrm{m} / \mathrm{v})$. In contrast, the sodium content in the cuttlefish bone extract solution was $27 \%$ less than that in a $\mathrm{NaCl}$ solution of the same degree of saltiness. Therefore, a novel salt substitute will be developed in future studies in accordance with the principles of bionics and a deep understanding of the salty taste interactions among key salty components in the cuttlefish bone extract.
\end{abstract}

Keywords Sodium $\cdot$ Salt $\cdot$ Substitute $\cdot$ Cuttlefish bone

Y. Zhang $\cdot$ Y. Yao $\cdot$ X. Guo $\cdot$ R. Wang $\cdot$ Z. Peng $(\bowtie)$

College of Food Science and Technology, Nanjing Agricultural

University, Nanjing 210095, People's Republic of China

e-mail: zqpeng@njau.edu.cn

\section{Y. Zhang}

Synergetic Innovation Center of Food Safety and Nutrition, Nanjing, People's Republic of China

Q. Cheng

College of Food and Nutritional Sciences, The University of Reading, Whiteknights, PO Box 217, Reading, Berkshire RG6 $6 \mathrm{AH}, \mathrm{UK}$

\section{Introduction}

Sodium chloride has many physiological functions, such as maintaining water and acid-base balance in the body. However, the excessive intake of sodium causes a rise in blood pressure [1], thereby increasing the risk of cardiovascular [2] and renal disease [3]. Methods of reducing sodium intake have attracted attention throughout the world. For example, the National Salt Reduction Initiative (NSRI) aims to reduce the salt content of the American diet by $20 \%$ over a 5-year period starting in 2010 [4]. The WHO has listed salt reduction as one of the five intervention priorities for the implementation of the European strategy on the prevention and control of noncommunicable diseases from 2012 to 2016 [5].

In recent decades, much research has been performed with the aim of developing salt substitutes. Most studies have been focused on the use of potassium chloride combined with $\mathrm{MgCl}_{2}$ or $\mathrm{CaCl}_{2}$ in meat products, cheeses, and breads [6-11]. K-lactate, L-lysine mono-hydrochloride, disodium inosinate, disodium guanylate, and taurine were also applied as salt substitutes in surimi and fermented sausages [12-15]. Another strategy for reducing sodium content was the use of herbs and spices [16]. The sensory perception of water extracts from plants was studied by Lee [17], who found that water extracts of saltwort, sea tangle, and kukoshi had a salty taste and that mixtures of these extracts contained $43 \%$ less sodium than $\mathrm{NaCl}$. Whether extracts from mineral-rich marine resources have a salty taste remains unknown. Therefore, in the present experiment, the saltiness of aqueous extracts from nine species of plants and marine animal shells was evaluated. The concentrations of the elements $\mathrm{Na}, \mathrm{K}, \mathrm{Mg}, \mathrm{Ca}, \mathrm{Zn}$, and $\mathrm{P}$ and amino acids in aqueous extracts of cuttlefish bone and clamshell were determined. 


\section{Materials and methods}

\section{Materials}

In total, nine materials were used in this study as listed in Table 1, including six marine sources, seaweed (Sargassum), kelp (ThallusLaminariae), clamshell (MeretrixmeretrixLinnaeus), oyster shell (Concha Ostreae), cuttlefish bone (Sepia esculenta hoyle), and Arabia cowry shell (Concha Mauritiae), and three land plants, inula flower (Flos Inulae), sanna leaf (Folium sennae), and semen cassiae (Catsia tora Linn). All materials were purchased from local supermarkets (Nanjing, China) and produced in various regions of China. The samples were in dry form and kept at room temperature before use.

\section{Methods}

\section{Preparation of aqueous extracts}

The materials were thoroughly cleaned with distilled water to remove dirt. After being sundried for 15 days, the materials were ground for $1 \mathrm{~min}$ in a disintegrator (HY-04B, Tianyuan Machinery Co., Ltd, Beijing, China) and then passed through a 40-mesh sieve. Twenty grams of each ground material was mixed with $30 \mathrm{ml}$ distilled water and extracted in a water bath at $100{ }^{\circ} \mathrm{C}$ for $4 \mathrm{~h}$. Vacuum filtration was applied, and the filtrate was dried in an oven (DHG-9240A, SANFA Scientific Instruments Co., Ltd, Shanghai, China) at $105^{\circ} \mathrm{C}$ until a constant weight was achieved.

\section{Subjects}

A total of 28 subjects (11 females) between 20 and 35 years of age were recruited from Nanjing Agricultural University. All subjects were untrained at the time

Table 1 The names and production of plants and marine animal shells

\begin{tabular}{|c|c|c|c|}
\hline Scientific name & Common name & Source & Production area \\
\hline Sargassum & Seaweed & Marine & Hainan \\
\hline ThallusLaminariae & Kelp & Marine & Hainan \\
\hline $\begin{array}{l}\text { Meretrixmeretrix- } \\
\text { Linnaeus }\end{array}$ & Clamshell & Marine & Hebei \\
\hline Concha Ostreae & Oyster shell & Marine & Hebei \\
\hline Catsia tora Linn & Semen cassiae & Terrestrial & Anhui \\
\hline $\begin{array}{l}\text { Sepia esculenta } \\
\text { hoyle }\end{array}$ & Cuttlefish bone & Marine & Hainan \\
\hline Flos Inulae & Inula flower & Terrestrial & Anhui \\
\hline Concha Mauritiae & Arabia cowry shell & Marine & Hainan \\
\hline Folium sennae & Sanna leaf & Terrestrial & Anhui \\
\hline
\end{tabular}

of recruitment but had experience in sensory evaluation. Prior to participation in the study, the subjects were presented with a series of coded $\mathrm{NaCl}$ solutions with $0.2,0.4$, $0.8,1.0$, and $1.5 \%(\mathrm{~m} / \mathrm{v}) \mathrm{NaCl}$ and were asked to rank the solutions in order from saltiest to least salty. The subjects who ranked the $\mathrm{NaCl}$ solutions in the correct order were accepted for further testing. A total of 20 subjects, nine females and 11 males, all between the ages of 20 and 33 years, were selected for the sensory evaluation. The subjects had no self-reported problems in taste or smell. The subjects were asked to refrain from eating foods or drinking beverages for at least $1 \mathrm{~h}$ prior to their scheduled session.

\section{Screening for the most salty aqueous extracts}

The saltiness of aqueous extracts derived from nine marine animal shells and plants was evaluated by a five-point hedonic scale test $(5=$ very strong, $4=$ strong, $3=$ moderate, 2 = weak, and $1=$ barely detectable). The stimuli, labelled with three-digit random codes, were presented in random order to cancel out any order effects. The saltiness of a $0.4 \mathrm{~mol} / \mathrm{L} \mathrm{NaCl}$ solution was used as a reference to represent moderate saltiness, based on a preliminary experiment. Samples of $1 \%$ of each aqueous extract $(\mathrm{m} / \mathrm{v})$ were prepared and served at room temperature. The subjects were asked to taste the reference solution $(0.4 \mathrm{~mol} / \mathrm{L}$ $\mathrm{NaCl}$ ) first and then rate the saltiness of the aqueous extract solution without taking the other tastes into account. They were asked to sip $5 \mathrm{ml}$ solutions $\left(20{ }^{\circ} \mathrm{C}\right)$, swished them gently for $2 \mathrm{~s}$, expectorate them, and then rate their stimulus intensity. There was a 60-s interval between stimuli during which the panellists were required to rinse their mouths with deionised water and eat a cracker, if desired. At the end of session, the aqueous extracts indicated by the panellists to have high saltiness were selected for the following tests.

\section{Sensory evaluation of saltiness}

To test the saltiness of the aqueous extracts, a degree of difference test (DOD) was carried out, following the work of Aust et al. [18] with some modifications. Five samples denoted by $\mathrm{X}, \mathrm{Y}_{1}, \mathrm{Y}_{2}, \mathrm{Y}_{3}$, and $\mathrm{Y}_{4}$ were prepared: $\mathrm{X}$ was the reference sample $(0.6 \% \mathrm{NaCl})(\mathrm{m} / \mathrm{v})$; $\mathrm{Y} 1$ was a control sample, and it was from the same batch as $\mathrm{X}$; and $\mathrm{Y}_{2}$, $\mathrm{Y}_{3}$, and $\mathrm{Y}_{4}$ were aqueous solutions of $1 \%$ clamshell extract $(\mathrm{m} / \mathrm{v}), 1.4 \%$ clamshell extract $(\mathrm{m} / \mathrm{v})$, and $0.6 \%$ cuttlefish bone $(\mathrm{m} / \mathrm{v})$, respectively. The task of the panellists was to determine the degree of saltiness difference between the reference sample $(X)$ and the four unknown samples $\left(Y_{1}\right.$, $\mathrm{Y}_{2}, \mathrm{Y}_{3}$, and $\left.\mathrm{Y}_{4}\right)$. The panellists were told that sample $\mathrm{X}$ was a reference sample and the coded samples $\left(\mathrm{Y}_{1}, \mathrm{Y}_{2}, \mathrm{Y}_{3}\right.$, and 
$\mathrm{Y}_{4}$ ) might or might not be different from sample $\mathrm{X}$. The stimuli were delivered using the sip-and-spit method. The panellists tasted sample $X$ first and then tasted each of the coded samples from $Y_{1}$ to $Y_{4}$. The samples presented from left to right were $\mathrm{X}, \mathrm{Y}_{1}, \mathrm{Y}_{2}, \mathrm{Y}_{3}$, and $\mathrm{Y}_{4}$. They received four $5 \mathrm{ml}$ samples for $3 \mathrm{~s}$ in order to compare them with the reference sample for saltiness intensity. There was a 60 -s inter-trial between stimuli, during which the panellists were required to rinse their mouths with deionised water and eat a cracker, if desired. The sensory scores were rated on a seven-point ordinal scale $(0, \pm 1, \pm 2, \pm 3)$ for which 0 represents no difference and \pm 3 represents an extreme difference (e.g. +3 , the intensity of the salty sample was significantly higher than the reference sample; -3 , the intensity of the salty sample was significantly lower than the reference sample).

\section{Evaluation of the degree of saltiness similarity}

To further study the degree of saltiness similarity between the cuttlefish bone aqueous extract and the $\mathrm{NaCl}$ solutions, four different concentrations $(0.4,0.6,0.8$, and $1 \%)$ of cuttlefish bone extract $(\mathrm{m} / \mathrm{v})$ and four different concentrations $(0.2,0.4,0.6$, and $0.8 \%)$ of $\mathrm{NaCl}$ solution $(\mathrm{m} / \mathrm{v})$ were used. The procedure for this evaluation was similar to that used for screening the most salty aqueous extracts.

\section{Comparison between subjective analysis and objective analysis in respect of saltiness}

A comparison between sensory evaluation and electronic tongue analysis of the salt solution and cuttlefish bone extract was designed. The same treatments tested for human sensory evaluation were evaluated by $\alpha$-Astree II electronic tongue (Alpha M.O.S. Co., Toulouse, France). A total of five liquid cross-selective sensors represented by $\mathrm{AB}, \mathrm{GA}, \mathrm{BB}, \mathrm{CA}$, and $\mathrm{DA}$ and an $\mathrm{Ag} / \mathrm{AgCl}$ reference electrode were used for this study. Each sensor had a specific organic membrane that could produce a response to five basic taste qualities (saltiness, sourness, bitterness, sweetness, and umami) in the sample solution in a specific manner. Any interaction at the membrane interface is detected by the sensor and converted into an electronic signal. $\mathrm{NaCl}$ solutions at $0.2,0.4,0.6$, and $0.8(\mathrm{~m} / \mathrm{v})$ and cuttlefish bone aqueous extracts at $0.4,0.6,0.8$, and $1 \%$ $(\mathrm{m} / \mathrm{v})$ were used in this experiment. The measurements were taken on samples of $80 \mathrm{ml}$. The electrodes were dipped for $120 \mathrm{~s}$ into each sample solution, and a total of seven cycles were performed. Before a new measurement sample was tested, the electrodes were rinsed for $120 \mathrm{~s}$ with distilled water. The data from the last three cycles were analysed using principal component analysis (PCA).
Extract component analysis

Determination of $\mathrm{Na}, \mathrm{K}, \mathrm{Mg}, \mathrm{Ca}, \mathrm{Zn}$, and $\mathrm{P}$

The content of $\mathrm{Na}, \mathrm{K}, \mathrm{Mg}, \mathrm{Ca}, \mathrm{Zn}$, and $\mathrm{P}$ was determined using inductively coupled plasma optical emission spectroscopy (ICP-OES) (Optima 2100DV, Perkin Elmer) with an axially viewed configuration according to the method described by Krachler [19] with some modifications. For this technique, $0.08 \mathrm{~g}$ of the extract was weighed and put into a crucible. The crucible was then heated with an electric stove, and a mixture of nitric acid and perchloric acid $(\mathrm{v} / \mathrm{v}=4: 1)$ was added for nitration until the solution was clear. Then, the sample solutions were allowed to cool and were diluted with $50 \mathrm{ml}$ of deionised water for analysis. Three replicates were applied to each sample.

The ICP-OES operational parameters were the following: $1300 \mathrm{w}$ radio frequency power; $15 \mathrm{~L} / \mathrm{min}$ plasma gas flow rate; $0.2 \mathrm{~L} / \mathrm{min}$ auxiliary gas flow rate; $0.8 \mathrm{~L} / \mathrm{min}$ nebuliser gas flow rate; and $1.5 \mathrm{~L} / \mathrm{min}$ sample uptake rate. The emission lines that were employed were $\mathrm{Na} 589.592$, K 769.896, Ca 422.673, Mg 285.213, Zn 213.857, and P $213.618 \mathrm{~nm}$.

\section{Amino acid analysis}

Amino acid profiles were determined according to the procedure previously described by Jaworska et al. [20], with slight modifications. In a test tube, $10 \mathrm{ml}$ of $\mathrm{HCl}$ was added to $50 \mathrm{mg}$ of the powdered extracts. The test tube was vacated by nitrogen, sealed, and placed in an oven at $110^{\circ} \mathrm{C}$ for $24 \mathrm{~h}$. The hydrolysates were evaporated to dryness under a vacuum at $60{ }^{\circ} \mathrm{C}$, dissolved in $1 \mathrm{ml}$ of buffer (sodium citrate buffer, $\mathrm{pH} 2.2$ ), and filtered through a 0.22 $\mu \mathrm{m}$ syringe filter before being applied to the Biochrom 31 amino acid analyser (Amersham, Britain). A volume of $20 \mu \mathrm{L}$ was injected into the amino acid analyser to estimate the amino acid profile of the samples. The amino acid profiles were determined according to the standard protocol of the manufacturer. Three replicates were applied to each sample.

\section{Statistical analysis}

For a hedonic scale test, significant differences $(P<0.05)$ between saltiness intensity for the "screening for the most salty aqueous extracts" experiment were identified using Duncan's multiple-range tests. The data of "evaluation of the degree of saltiness similarity" were analysed using repeated-measures ANOVA, and the differences between the treatments were assessed using Duncan's multiplerange tests. The correlation between sensory and chemical data was analysed with the commercial software SPSS 
13.0. For the DOD, significant differences $(\alpha=0.05)$ between samples and the control were assessed using least significant difference (LSD) test.

\section{Results and discussion}

Screening for the most salty aqueous extract

The sensory saltiness of aqueous extracts of nine plants and marine animal shells is presented in Fig. 1. The saltiness of the clamshell extract and cuttlefish bone extract were $1.28 \pm 0.21$ and $3.12 \pm 0.56$, respectively. The saltiness of the oyster shell and Arabia cowry shell extracts were 5.8 and $5.1 \%$ of that of the cuttlefish bone extract, respectively, although they were both from marine sources. The marine and terrestrial plants, including seaweed, kelp, inula flower, semen cassiae, and sanna leaf, were found to have weak saltiness. The cause of the difference in saltiness among the samples might be due to the species, origins, and also physiological functions. Cuttlefish bone refers to the internal shell or bone of the cuttlefish (Sepia Officinalis L.) [21], which is rich in minerals [22]. In Lee's opinion, large quantities of minerals might lead to a salty taste for marine organisms [23]. Based on the saltiness evaluation,

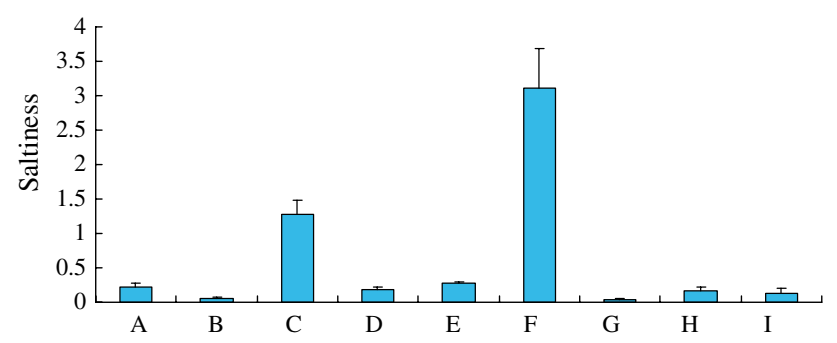

Fig. 1 Saltiness of aqueous extract of nine plants and marine animal shells $(n=20)$. A $=$ seaweed, $\mathrm{B}=$ kelp, $\mathrm{C}=$ clamshell, $\mathrm{D}=$ oyster shell, $\mathrm{E}=$ semen cassiae, $\mathrm{F}=$ cuttlefish bone, $\mathrm{G}=$ inula flower, $\mathrm{H}=$ arabia cowry shell, $\mathrm{I}=$ sanna leaf

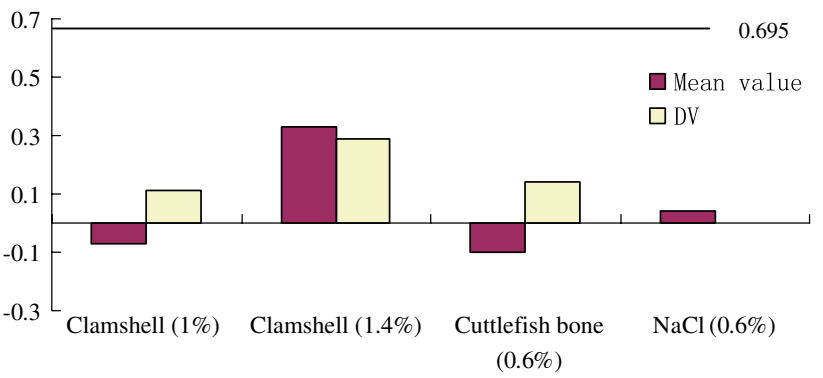

Fig. 2 Saltiness intensity of the clamshell and cuttlefish bone extract solutions $(n=20)$. $\operatorname{LSD}_{0.05}=0.695 \alpha=0.05 . \mathrm{NaCl}(0.6 \%)$ is the control sample. DV is the difference value in saltiness between the clamshell or cuttlefish bone and $0.6 \% \mathrm{NaCl}$ (control sample) the clamshell and cuttlefish bone aqueous extracts with a high saltiness were selected for saltiness evaluation and component analysis.

Saltiness evaluation and component determination of the aqueous extracts

In humans, $\mathrm{NaCl}$ does not generate the quality of saltiness until its concentration exceeds $40 \mathrm{mmol} / \mathrm{L}$ [24]. Based on this, $0.6 \% \mathrm{NaCl}$ was used as the control in this study. According to the results of the saltiness evaluation of nine aqueous extracts, $0.6 \%$ cuttlefish bone extract and 1 and $1.4 \%$ clamshell extract solutions were used as the samples for evaluating the difference in perceived saltiness from control. As shown in Fig. 2, the difference value (DV) in saltiness between $1.4 \%$ clamshell extract and control was biggest and the DV was less than $\mathrm{LSD}_{0.05}$ (0.695). Furthermore, the result of the least significant difference test (LSD) showed that the difference values between the samples and the control were all less than $\mathrm{LSD}_{0.05}$ (Fig. 2), i.e. there was no significant difference in saltiness between the samples and the control. In other words, the saltiness between these samples and the control was similar. In contrast, the sodium content of the $0.6 \%$ cuttlefish bone extract was the lowest among these samples. The sodium content of the $\mathrm{NaCl}$ control solution was $393.3 \mathrm{mg} / \mathrm{g}$. Table 3 shows that the sodium levels of the clamshell and cuttlefish bone extracts were $262.5 \mathrm{mg} / \mathrm{g}$ and $287.5 \mathrm{mg} / \mathrm{g}$ (dry matter), respectively. Therefore, the sodium content of the $0.6 \%$ cuttlefish bone extract and 1 and $1.4 \%$ clamshell extract were 1.725 , 2.625 , and $3.675 \mathrm{mg} / \mathrm{mL}$, respectively, and the control, $0.6 \% \mathrm{NaCl}$, contained $2.359 \mathrm{mg} / \mathrm{ml}$ sodium. The sodium level of the cuttlefish bone extract solution was $73 \%$ of that of the $\mathrm{NaCl}$ solution in circumstances of similar saltiness.

The contents of the elements $\mathrm{Na}, \mathrm{K}, \mathrm{Mg}, \mathrm{Ca}, \mathrm{Zn}$, and $\mathrm{P}$ and of amino acids were also determined in the present study (Table 2). The contents of potassium, magnesium, and phosphorus in the cuttlefish bone extract were approximately six times, eighty-six times, and three times that of the clamshell extract, respectively. The contents of elements $\mathrm{Na}, \mathrm{K}, \mathrm{P}$, and $\mathrm{Zn}$ in the cuttlefish bone aqueous extract were in line with the previous finding of Stallard [22], who reported that the sodium percentage was highest for the dried matter of cuttlefish bone, followed by potassium, phosphorus, and zinc except calcium and magnesium. Regarding the contents of amino acids, the quantitated amounts of 13 amino acids were all higher than that in clamshell extract. And the levels of Phe, Lys, and His were high among 13 amino acids in cuttlefish bone extract. The individual amino acids have different tastes [25-28]. Ala and Leu at the same fixed concentration $(0.3 \%)$ are sweet and bitter in taste, respectively, although it is known that the taste quality may vary with concentration [29]. Lys, 
Table 2 The contents of element and amino acids in cuttlefish bone extract and clamshell extract $(n=3)$

\begin{tabular}{|c|c|c|}
\hline & \multicolumn{2}{|l|}{ Sample } \\
\hline & Cuttlefish bone extract & Clamshell extract \\
\hline \multicolumn{3}{|c|}{ Element (dry matter, mg/g) } \\
\hline $\mathrm{Na}$ & $287.5 \pm 17.3^{\mathrm{a}}$ & $262.5 \pm 20.2^{b}$ \\
\hline $\mathrm{K}$ & $60.5 \pm 0.5^{\mathrm{a}}$ & $10.4 \pm 0.8^{\mathrm{b}}$ \\
\hline $\mathrm{Ca}$ & $10.9 \pm 1.8^{\mathrm{ab}}$ & $14.2 \pm 1.1^{\mathrm{a}}$ \\
\hline $\mathrm{Mg}$ & $17.2 \pm 1.1^{\mathrm{a}}$ & $0.3 \pm 0.02^{\mathrm{b}}$ \\
\hline $\mathrm{Zn}$ & $0.11 \pm 0.02^{\mathrm{a}}$ & $0.099 \pm 0.006^{\mathrm{a}}$ \\
\hline $\mathrm{P}$ & $0.74 \pm 0.03^{\mathrm{a}}$ & $0.25 \pm 0.04^{\mathrm{b}}$ \\
\hline \multicolumn{3}{|c|}{ Amino acid $(\mathrm{mg} / \mathrm{g})^{*}$} \\
\hline Asp & $0.07 \pm 0.02$ & $0.05 \pm 0.01$ \\
\hline Ser & $0.17 \pm 0.03$ & N.D. \\
\hline Glu & $0.94 \pm 0.08$ & N.D. \\
\hline Gly & $0.17 \pm 0.02$ & N.D. \\
\hline Ala & $0.20 \pm 0.04$ & N.D. \\
\hline Val & $0.48 \pm 0.08$ & N.D. \\
\hline Ile & $0.05 \pm 0.02$ & N.D. \\
\hline Leu & $0.09 \pm 0.02$ & N.D. \\
\hline Tyr & $0.23 \pm 0.04$ & N.D. \\
\hline Phe & $1.23 \pm 0.21$ & $0.52 \pm 0.06$ \\
\hline Lys & $1.69 \pm 0.17$ & N.D. \\
\hline His & $1.47 \pm 0.22$ & $0.16 \pm 0.03$ \\
\hline Arg & $0.08 \pm 0.02$ & N.D. \\
\hline
\end{tabular}

N.D. not detected

a-b Values with the same superscript within the same line indicate not significant difference between cuttlefish bone extract and clamshell extract treatments $(P>0.05)$

* The structures of Trp, Gln, and Asn were destroyed in acid hydrolysis procedure. Pro, Thr, Met, and Cys were not detected in both cuttlefish bone extract and clamshell extract

His, and Arg were salty with little sour or bitter [26]. These three amino acids and others might contribute to salty taste and saltiness of cuttlefish bone extract. It was possible that component interaction between two amino acids, between an amino acid and element, and between two elements was the cause of the saltiness intensity of the cuttlefish bone extract being higher than that of the clamshell extract. Research on the effect of saltiness on the interactions between the key salty components in cuttlefish bone will be reported in a future publication.

Evaluation of the degree of saltiness similarity

The saltiness evaluations of different concentrations of cuttlefish bone extract solutions and $\mathrm{NaCl}$ solutions are shown in Fig. 3. The saltiness of cuttlefish bone extracts of $0.4-1.0 \%$ increased linearly $(P<0.05)$, which was in accordance with the increasing saltiness tendency of $\mathrm{NaCl}$.

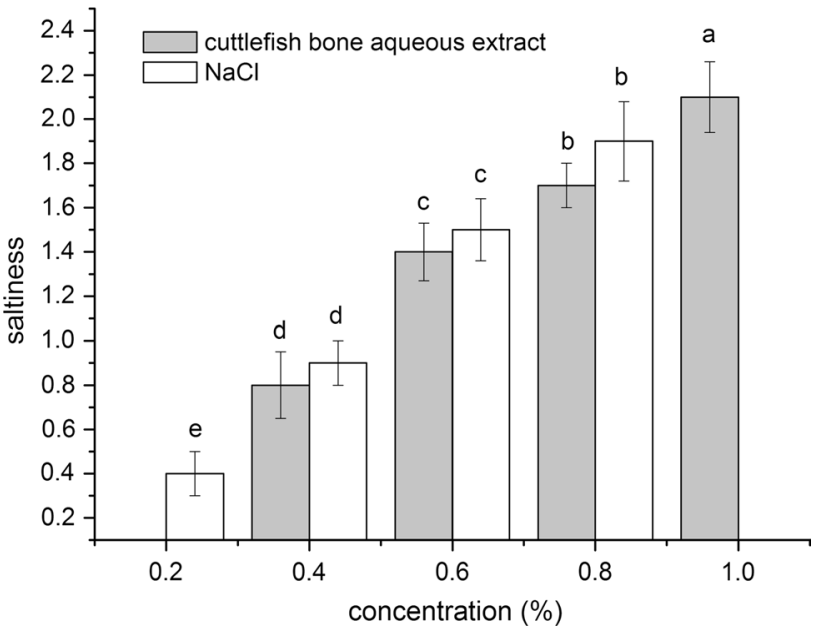

Fig. 3 The saltiness of cuttlefish bone extracts and $\mathrm{NaCl}$ for different concentrations $(n=20)$

In $0.4,0.6$, and $0.8 \%$ solutions, there was no significant difference $(P>0.05)$ in saltiness between the cuttlefish bone extract and $\mathrm{NaCl}$. That is to say, the cuttlefish bone extract and $\mathrm{NaCl}$ had similar levels of saltiness at the same concentrations.

The same treatments for the evaluation of the degree of saltiness similarity were evaluated by electronic tongue. The relationships between the cuttlefish bone aqueous extract and $\mathrm{NaCl}$ were identified using principal component analysis (PCA; Fig. 4). PC1 explained $64.122 \%$ of the variances, and $\mathrm{PC} 2$ explained $28.655 \%$ of the variances. Therefore, the two-dimensional plot represented by the PC1 and PC2 scores could describe $92.78 \%$ of the information obtained from the original data, indicating the effectiveness of the electronic tongue test. Similarly characterised samples were closely located in the PCA plot. Correspondingly, it was shown that the distance between $0.8 \%$ cuttlefish bone extract solution and $0.8 \% \mathrm{NaCl}$ was the smallest (Table 3). It meant that the saltiness between $0.8 \%$ cuttlefish bone extract and $0.8 \% \mathrm{NaCl}$ was most similar. In contrast, in difference of degree test (Fig. 2), we thought that the saltiness of $0.6 \%$ cuttlefish bone extract solution was most similar to $0.6 \% \mathrm{NaCl}$ solution in spite of the difference value between $1 \%$ clamshell and $0.6 \% \mathrm{NaCl}$ because the sodium content of $1 \%$ clamshell extract was higher than that of $0.6 \%$ cuttlefish bone extract. Furthermore, from Fig. 3, the saltiness of $0.6 \% \mathrm{NaCl}$ was 0.1 more than that of $0.6 \%$ cuttlefish bone extract. Taken together, it was alternative that the saltiness of $0.6 \%$ cuttlefish bone extract solution was most similar to $0.6 \% \mathrm{NaCl}$ solution because human tasting always had the last word although E-tongue might be a more objective instrumental method.

The relationship between the subjective and objective data was identified with SPSS software. Based on the PCA, 


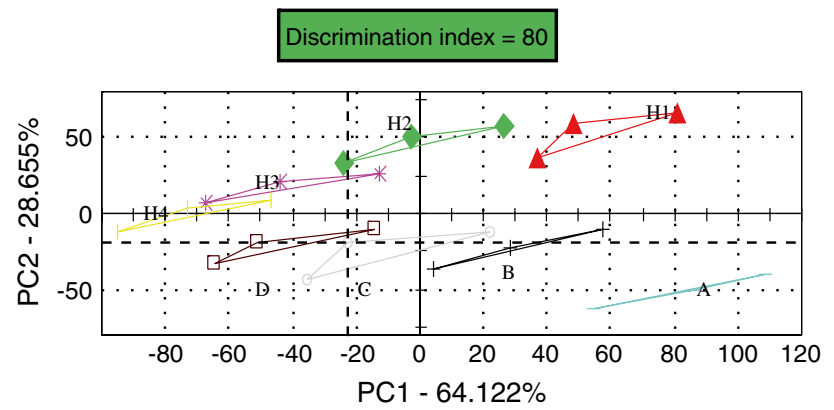

Fig. 4 PCA of samples of different concentrations. $\mathrm{A}=0.2 \% \mathrm{NaCl}$; $\mathrm{B}=0.4 \% \mathrm{NaCl} ; \mathrm{C}=0.6 \% \mathrm{NaCl} ; \mathrm{D}=0.8 \% \mathrm{NaCl}$. $\mathrm{H} 1=0.4 \%$ cuttlefish bone; $\mathrm{H} 2=0.6 \%$ cuttlefish bone; $\mathrm{H} 3=0.8 \%$ cuttlefish bone; $\mathrm{H} 4=1 \%$ cuttlefish bone

Table 3 Distance between cuttlefish bone extract and $\mathrm{NaCl}$

\begin{tabular}{llll}
\hline Product names & $\begin{array}{l}\text { Reference } \\
\text { samples }\end{array}$ & Distances & $\begin{array}{l}\text { Pattern discrimina- } \\
\text { tion index }(\%)\end{array}$ \\
\hline $\begin{array}{l}0.4 \% \text { cuttlefish } \\
\text { bone }\end{array}$ & $0.2 \% \mathrm{NaCl}$ & 76.00 & 25.83 \\
& $0.4 \% \mathrm{NaCl}$ & 72.00 & 24.28 \\
& $0.6 \% \mathrm{NaCl}$ & 85.00 & 30.56 \\
$0.6 \%$ cuttlefish & $0.8 \% \mathrm{NaCl}$ & 104.00 & 40.31 \\
bone & $0.4 \% \mathrm{NaCl}$ & 104.00 & 41.40 \\
& $0.6 \% \mathrm{NaCl}$ & 74.00 & 34.02 \\
$0.8 \%$ cuttlefish & $0.2 \% \mathrm{NaCl}$ & 78.00 & 26.70 \\
bone & $0.4 \% \mathrm{NaCl}$ & 124.00 & 52.45 \\
& $0.6 \% \mathrm{NaCl}$ & 104.00 & 44.72 \\
& $0.8 \% \mathrm{NaCl}$ & 63.00 & 30.00 \\
$1.0 \%$ cuttlefish & $0.2 \% \mathrm{NaCl}$ & 138.00 & 57.59 \\
bone & $0.4 \% \mathrm{NaCl}$ & 120.00 & 51.37 \\
& $0.6 \% \mathrm{NaCl}$ & 89.00 & 36.57 \\
& $0.8 \% \mathrm{NaCl}$ & 66.00 & 24.80 \\
\hline
\end{tabular}

the comprehensive evaluation function was $F=\eta_{1} /\left(\eta_{1+} \eta_{2}\right)$ $* F_{1}+\left[1-\eta_{1} /\left(\eta_{1}+\eta_{2}\right)\right] * F_{2}\left(\eta_{1}\right.$ : the contribution of the first PC; $\eta_{2}$ : the contribution of the second PC; $F_{1}$ : the first principal component score; $F_{1}$ : the second principal component score). The correlation coefficients between the $\mathrm{F}$ value and saltiness scores were calculated. The coefficient for cuttlefish bone aqueous extract was 0.9934 , and the coefficient for $\mathrm{NaCl}$ was 0.9994 . It was shown that there was a strong positive correlation between the sensory and instrumental data.

\section{Conclusion}

Over the course of the recent decades, research on reducing salt consumption has become a key issue in academic studies as well as government initiatives throughout the world.
The findings of the present study indicated that the cuttlefish bone aqueous extracts tasted the saltiest among seaweed, kelp, clamshell, oyster shell, semen cassiae, cuttlefish bone, inula flower, Arabia cowry shell, and sanna leaf samples. Meanwhile, $0.6 \%$ cuttlefish bone aqueous extract was equivalent in saltiness to $0.6 \% \mathrm{NaCl}$. In contrast, the sodium content of cuttlefish bone was $73 \%$ of that of $\mathrm{NaCl}$ at the same level of saltiness. The results from the component determination of the aqueous extracts suggested that further research on the salty taste interactions among key salty components in the cuttlefish bone extract could be useful for developing a novel salt substitute.

Acknowledgments The search was supported by the earmarked fund for Modern Agro-Industry Technology Research System (NYCYTX-38), Ministry of Agriculture, China.

\section{Conflict of interest None.}

Compliance with Ethics Requirements This article does not contain any studies with human or animal subjects.

Open Access This article is distributed under the terms of the Creative Commons Attribution License which permits any use, distribution, and reproduction in any medium, provided the original author(s) and the source are credited.

\section{References}

1. He FJ, MacGregor GA (2009) A comprehensive review on salt and health and current experience of worldwide salt reduction programmes. J Hum Hyperten 23:363-384

2. Cook NR, Cutler JA, Obrzanek E, Buring JE, Rexrode KM, Kumanyika SK, Appel LJ, Whelton PK (2007) Long term effects of dietary sodium reduction on cardiovascular disease outcomes: observational follow-up of the trials of hypertension prevention (TOHP). BMJ 334:885

3. Cianciaruso B, Bellizzi V, Minutolo R, Tavera A, Capuano A, Conte G, Nicola LD (1998) Salt intake and renal outcome in patients with progressive renal disease. Miner Electrolyte Metab 24:296-301

4. Wenther JB (2010) Reducing salt content in food threatens processed meat industry. American Association of Meat Processors, Elizabethtown

5. WHO. 2011 Reducing salt intake. Available at: http://www. euro.who.int/en/what-we-do/health-topics/disease-prevention/ nutrition/news/news/2011/10/reducing-salt-intake

6. Aliño M, Grau R, Fuentes A, Barat JM (2010) Influence of lowsodium mixtures of salts on the post-salting stage of dry-cured ham progress. J Food Eng 99:198-205

7. Guàrdia MD, Guerrero L, Gelabert J, Gou P, Arnau J (2008) Sensory characterisation and consumer acceptability of small calibre fermented sausages with $50 \%$ substitution of $\mathrm{NaCl}$ by mixtures of $\mathrm{KCl}$ and potassium lactate. Meat Sci 80:1225-1230

8. Gou P, Guerrero L, Gelabert J, Arnau J (1996) Potassium chloride, potassium lactate and glycine as sodium chloride substitutes in fermented sausages and in dry-cured pork loin. Meat Sci 42:37-48

9. Puolanne E, Saarela E, Ruusunen M (1988) The effect of NaCl$\mathrm{KCl}-\mathrm{MgSO} 4-m i x t u r e\left(\operatorname{Pan}^{\circledR}\right)$ on the quality of cooked sausage. 
In Proceedings of the 34th international congress of meat science and technology. Part B (pp. 302-304). Brisbane, Australia

10. Salovaara H (1982) Sensory limitations to replacement of sodium with potassium and magnesium in bread. Cereal Chem 59:427-430

11. Gomes AP (2011) Manufacture of low-sodium Minas fresh cheese: effect of the partial replacement of sodium chloride with potassium chloride. J Dairy Sci 94:2701-2706

12. Tahergorabi R, Jaczynski J (2012) Physicochemical changes in surimi with salt substitute. Food Chem 132:1281-1286

13. Tahergorabi R, Beamer SK, Matak KE, Jaczynski J (2012) Salt substitution in surimi seafood and its effects on instrumental quality attributes. Food Sci Technol 48:175-181

14. Campagnol PCB, Santos BAD, Morgano MA, Terra NN, Pollonio MAR (2011) Application of lysine, taurine, disodium inosinate and disodium guanylate in fermented cooked sausages with $50 \%$ replacement of $\mathrm{NaCl}$ by $\mathrm{KCl}$. Meat Sci 87:239-243

15. Campagnol PCB, Santos BAD, Terra NN, Pollonio MAR (2012) Lysine, disodium guanylate and disodium inosinate as flavor enhancers in low- sodium fermented sausages. Meat Sci 91:334-338

16. President and fellows of Harvard College (2006) Salt substitutes deserve a place at the table. Harvard Heart Letter 17:4

17. Lee GH (2010) A salt substitute with low sodium content from plant aqueous extracts. Food Res Int 44:537-543

18. Aust LB, Beard SA, Washam RW (1985) Degree of difference test method in sensory evaluation of heterogeneous product types. J Food Sci 50:511-513

19. Krachler M, Winckel SV, Cardinale M, Lynch B, Murakami $\mathrm{T}$ (2012) Method development for the determination of alkali metals in samples from pyrochemical reprocessing using ICPOES and comparison with sector field ICP-MS. Microchem J 105:9-14

20. Jaworska G, Bernas E, Mickowska B (2011) Effect of production process on the amino acid content of frozen and canned Pleurotus ostreatus mushrooms. Food Chem 125:936-943

21. Birchall JD, Thomas NL (1983) On the architecture and function of cuttlefish bone. J Mater Sci 18:2081-2086

22. Stalld C (2003) An investigation into the nutrient intake, output and approximate digestibilities of the Polynesian tree snail (Partula clara). Proceeding of the fifth annual symposium on zoo research. Session Three, Feeding and Nutrition, pp 77-83

23. Lee CH, Hwang JH, Oh SW, Kim IH, Kim Y, Yu KW (2004) Chemical properties and immunological activities of hot water extract leaves of saltwort. Food Sci Biotechnol 13:167-171

24. Mccauthey SA, Scott TR (1998) The taste of sodium. Neurosci Biobehav Rev 22:663-676

25. Schiffman SS, Engelhard HH (1976) Taste of dipeptides. Physiol Behav 17:523-535

26. Schiffman SS, Dackis C (1975) Taste of nutrients: amino acids, vitamins, and fatty acids. Percept Psychophys 17:140-146

27. Ninomiya T, Ikeda S, Yamaguchi S, Yoshikawa T (1966) Study of taste of various kinds of amino acids, in: Proceedings of the 7th Congress Sensory Tests, pp. 109-123

28. Toko K (2000) Biomimetic Sensor Technology. Cambridge Univ Press, Cambridge

29. Solms J (1969) The taste of amino acids, peptides, and proteins. J Agric Food Chem 17:686-688 